\title{
A population-based analysis of the health experience of African Nova Scotians
}

\author{
Steve Kisely MD MSc, Mikiko Terashima MSc, Don Langille MD MHSc
}

$\infty$ See related commentary by Bonham and Ramos, page 629

\section{ABSTRACT}

Background: People of African descent living in Britain and the United States have higher rates of morbidity from chronic disease than among the general population. We investigated whether the same applied to people of African descent living in a Canadian province.

Methods: We used administrative data to calculate 10-year cumulative incidence rate ratios for the period 1996-2005 for treated circulatory disease, diabetes mellitus and psychiatric disorders in Preston (population 2425), a community of predominantly African Nova Scotians. We used data for the province of Nova Scotia as a whole as the population reference standard. We also calculated 10-year incidence rate ratios for visits to family physicians and specialists and for admissions to hospital. We compared these findings with those in 7 predominantly white communities in Nova Scotia with otherwise similar socio-economic characteristics.

Results: In the province as a whole, we identified 787787 incident cases for the 3 disease groups over the 10-year period. Incidence rate ratios for the community of interest relative to the provincial population were significantly elevated for the 3 diseases: circulatory disease $(1.19,95 \% \mathrm{Cl}$ 1.08-1.29), diabetes $(1.43,95 \% \mathrm{Cl} 1.21-1.64)$ and psychiatric disorders $(1.13,95 \% \mathrm{Cl} 1.06-1.20)$. Incidence rate ratios in the community of interest were also higher than those in the comparison communities. Visits to family physicians and specialists for circulatory disease and diabetes were similarly elevated, but the pattern was less clear for visits for psychiatric disorders and hospital admissions.

Interpretation: African Nova Scotians had higher morbidity levels associated with treated disease, which could not be explained by socio-economic characteristics, recent immigration or language. Apart from psychiatric disorders, use of specialist services was consistent with morbidity. Further study is needed to investigate the relative contribution of genetic, biological, behavioural, psychosocial and environmental factors.

Une version française de ce résumé est disponible à l'adresse www.cmaj.ca/cgi/content/full/179/7/653/DC1

CMAJ 2008;179(7):653-8

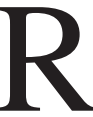

esidents of African descent are the largest minority in Nova Scotia, ${ }^{1}$ yet their health status is generally unknown. Research on the health of the African diaspora originates primarily in the United States and the
United Kingdom. Diseases and conditions of interest that have been examined include circulatory disease, diabetes mellitus and psychiatric disorders. ${ }^{2,3}$ Even allowing for social disadvantage, people of African descent have higher rates of morbidity or mortality (or both) from these disorders. ${ }^{2-4}$ Existing Canadian data reflect overall self-reported use of health services or health status, without comparison by diagnosis. ${ }^{4,5}$

We hypothesized that rates of circulatory disease, diabetes and psychiatric disorders would be higher in Preston, Nova Scotia, a community whose population is predominantly African Nova Scotians, than for other communities in the province with otherwise similar socio-economic characteristics and a predominantly white population. We also investigated whether use of specialist health services for these conditions was consistent with incidence. Given the 200-year history of African Nova Scotias in the province, we speculated that recent immigration and language were unlikely to be contributors to morbidity and use of health services. ${ }^{6}$ These people are descended largely from US refugees who settled in many areas of the province from 1813 to $1816,{ }^{6}$ with little subsequent influx. Later immigrants make up only $5 \%$ of the Nova Scotian population, with Europe providing most of the recent immigrants, followed by Asia and the Middle East. ${ }^{?}$

\section{Methods}

In this retrospective cohort study, we used a population-based approach to calculate age- and sex-standardized 10-year cumulative incidence rate ratios for Preston (population predominantly African Nova Scotians) and 7 comparison communities elsewhere in Nova Scotia (population predominantly white), both relative to the overall provincial population. We also investigated access to family physicians and specialists and use of hospital services.

\section{Data sources}

We used the following administrative databases at the Population Health Research Unit, Dalhousie University: physician billings for specialists and family physicians, including service date and diagnosis; the Discharge Abstract Database of

From the Department of Community Health and Epidemiology (Kisely, Terashima, Langille), Dalhousie University, Halifax, NS; and the School of Medicine (Kisely), Griffith University, Meadowbrook, Queensland, Australia 
admission type and diagnosis; and the Mental Health Outpatient Information System of demographic information, diagnoses and mental health clinician visits. We used the Nova Scotia Community Counts website to identify population denominators and areas of concentration of African Nova Scotians across the province. ${ }^{8}$

Health Canada ${ }^{9}$ and the Public Health Agency of Canada ${ }^{10}$ have both used administrative data sets for surveillance of chronic diseases. Although the data used by both agencies were for billing, rather than surveillance, they have proved highly accurate for disease surveillance, both over time and

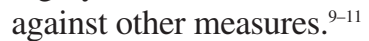

\section{Selection of cases}

For all Nova Scotians of all ages who had contact with a family physician or received inpatient or outpatient services from 1996 to 2005, we calculated population-standardized rates for the following conditions, according to the most responsible diagnosis: circulatory disease, including cardiovascular disease; hypertensive disease; cerebrovascular disease or peripheral vascular disease; diabetes mellitus, especially type 2; and psychiatric disorders (Box 1). The codes that we used for diabetes and psychiatric disorders were the same as those used by Health Canada ${ }^{9}$ and the Public Health Agency of Canada ${ }^{10}$ for surveillance of these conditions. We defined overall incidence as any first contact for each condition during the period of interest. For each condition, we excluded anyone who appeared in any database in the year preceding the study (i.e., 1995). The disease groups were considered separately, so it was possible, for example, that someone could be counted for both circulatory disease and diabetes.

\section{Selection of communities}

We defined African Nova Scotians as anyone who selfidentified as "black" in the 2001 census. We based our analysis on an area unit called "community," as defined by Nova Scotia Community Counts, ${ }^{8}$ to which census data were recalibrated. In 2001, there were 19670 African Nova Scotians.

Preston (population 2425) is the one community in the province, as defined by Nova Scotia Community Counts,

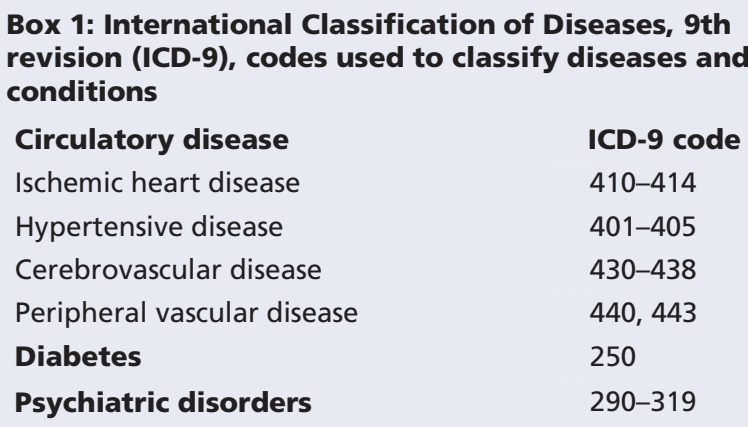

where the majority of residents are of African descent $(86.1 \%)$. By comparison, $2.2 \%$ of the provincial population meets this definition. ${ }^{8}$ Guysborough has the next highest percentage of African Nova Scotian residents (13.9\%), a far lower figure than that for Preston. We selected a total of 7 comparison communities, including Guysborough, on the basis of similarities to Preston in terms of population size, median household income, educational attainment (proportion of people over 20 years of age with less than a high school diploma) and unemployment rate, based on 2001 census data (Table 1). We also considered proximity to a hospital in selecting the comparison communities.

\section{Calculation of rates and ratios for individual communities}

We used point-location geocoding and Statistics Canada's Postal Code Conversion File ${ }^{12}$ to count each visit (for the 3 types of visit for each of the 3 disease groups of interest, plus outpatient visits taken from the Mental Health Outpatient Information System) and overall incidence (for the 3 disease groups) in Preston and the comparison communities. The Postal Code Conversion File links each 6-character postal code to standard census geographic areas and then probabilistically assigns a latitude and longitude point to the postal code, weighted for the number of residents in the area of interest. We improved accuracy by running the conversion file a sufficient number of times $(n=10)$ to achieve stability of

Table 1: Socio-economic data for Preston and 7 comparison comm unities in Nova Scotia

\begin{tabular}{|c|c|c|c|c|c|}
\hline Community & $\begin{array}{l}\text { No. (\%) African } \\
\text { Nova Scotians }\end{array}$ & $\begin{array}{c}\text { Total } \\
\text { population }\end{array}$ & $\begin{array}{c}\text { Median } \\
\text { household } \\
\text { income, \$ }\end{array}$ & $\%$ unemployed & $\begin{array}{l}\text { \% with less than } \\
\text { high school } \\
\text { diploma* }\end{array}$ \\
\hline Preston & $2090 \quad(86.2)$ & 2425 & 36502 & 8.4 & 44.8 \\
\hline Guysborough & 281 (13.9) & 2020 & 31601 & 8.3 & 43.5 \\
\hline Canso & $10 \quad(0.6)$ & 1693 & 32375 & 14.3 & 59.6 \\
\hline Sherbrooke & $9 \quad(0.5)$ & 1709 & 33268 & 10.8 & 54.8 \\
\hline Louisdale & $2 \quad(0.1)$ & 1823 & 29990 & 12.5 & 42.7 \\
\hline Digby Neck & $\begin{array}{ll}0 & (0.0)\end{array}$ & 1923 & 29417 & 8.4 & 50.7 \\
\hline New Ross & $0 \quad(0.0)$ & 1475 & 28474 & 6.5 & 48.0 \\
\hline Tatamagouche & $\begin{array}{ll}0 & (0.0)\end{array}$ & 2027 & 29171 & 6.9 & 48.4 \\
\hline Provincial total & 19794 & 908005 & 39908 & 5.6 & 31.7 \\
\hline
\end{tabular}

${ }^{*}$ Calculated on the basis of those 20 years of age and older. 
results, defined as a change in the standard deviation of less than 1 in the final iteration.

We then calculated overall incidence rate ratios for Preston and the comparison communities relative to Nova Scotia's entire population for each disease group, using indirect ageand-sex standardization. We then compared the values for Preston with those for the comparison communities. We also calculated rate ratios for family physician visits, specialist visits and hospital admissions for each disease group, again using indirect age-and-sex standardization. As for overall incidence, we excluded anyone who appeared in any database in the year preceding the study period. We calculated $95 \%$ confidence intervals (CIs) for the incidence rate ratios to determine any significance in the difference between ratios, assuming a normal distribution for observed counts greater than 100 and a Poisson distribution for those less than $100 .{ }^{13}$ We did the same for family physician visits, specialist visits and hospital admissions. Twenty-four rate ratios had counts of less than 100, and 12 had counts of less than 30. Those with counts less than 30 were excluded from the final results reported here.

\section{Results}

\section{Overall morbidity}

In total, we identified 787787 incident cases in Nova Scotia for the 3 disease groups over 10 years. Of these cases, $98.4 \%$ (775 044) had a residential postal code. Of those with a residential postal code, $430118(55.5 \%)$ involved women. In order of frequency, there were 449621 incident cases of a psy- chiatric disorder, 250393 of circulatory disease and 75030 of diabetes.

\section{Circulatory disease}

The overall incidence rate for circulatory disease was significantly higher in Preston than in Nova Scotia as a whole (rate ratio 1.19) (Table 2). It was also significantly higher than that in the comparison communities (Table 2). The greater overall incidence rate for Preston was reflected in significantly higher incidence rates for family physician and specialist visits than in the province as a whole, as well as significantly higher incident rates for family physician visits than in the comparison communities. The incidence rate for hospital admissions in Preston did not differ from those for the province or the comparison communities.

\section{Diabetes}

The results for diabetes (Table 2) were similar to those for circulatory disease. The overall incidence rate for diabetes was significantly higher in Preston than in the province as a whole (rate ratio 1.43) and in the comparison communities (Table 2). The incidence rates for family physician and specialist visits were also significantly higher than those for the province and the comparison communities (Table 2). The incidence rate for specialist visits in Preston was almost double that for the province as a whole.

\section{Psychiatric disorders}

The overall incidence rate for psychiatric disorders was significantly higher in Preston than in the province (rate ratio

Table 2: Incidence rate ratios for circulatory disease, diabetes mellitus and psychiatric disorders for people of African descent living in Preston, Nova Scotia, and for 7 comparison communities elsewhere in Nova Scotia, relative to the provincial population as a whole

\begin{tabular}{|c|c|c|c|c|}
\hline \multirow{2}{*}{$\begin{array}{l}\text { Indicator of care } \\
\text { Circulatory disease }\end{array}$} & \multicolumn{4}{|c|}{ Community; incidence rate ratio ( $95 \%$ confidence interval) } \\
\hline & \multicolumn{2}{|c|}{ Preston } & \multicolumn{2}{|c|}{ Comparison communities } \\
\hline Overall diagnosis & 1.19 & $(1.08-1.29)$ & 1.00 & $(0.97-1.01)$ \\
\hline Family physician visits & 1.21 & $(1.11-1.33)$ & 0.99 & $(0.96-1.01)$ \\
\hline Specialist visits & 1.23 & $(1.06-1.40)$ & 1.05 & $(1.00-1.08)$ \\
\hline Hospital admissions & 0.92 & $(0.69-1.21)$ & 1.08 & $(1.00-1.12)$ \\
\hline \multicolumn{5}{|l|}{ Diabetes mellitus } \\
\hline Overall diagnosis & 1.43 & $(1.21-1.64)$ & 0.99 & $(0.93-1.01)$ \\
\hline Family physician visits & 1.42 & $(1.22-1.63)$ & 0.94 & $(0.88-0.96)$ \\
\hline Specialist visits & 1.97 & $(1.59-2.34)$ & 1.32 & $(1.22-1.37)$ \\
\hline Hospital admissions & NR & & 1.16 & $(0.92-1.45)$ \\
\hline \multicolumn{5}{|l|}{ Psychiatric disorders } \\
\hline Overall diagnosis & 1.13 & $(1.06-1.20)$ & 0.88 & $(0.86-0.89)$ \\
\hline Family physician visits & 1.13 & $(1.06-1.20)$ & 0.87 & $(0.84-0.87)$ \\
\hline Specialist visits & 0.75 & $(0.62-0.89)$ & 0.71 & $(0.66-0.74)$ \\
\hline Mental health service visits & 0.56 & $(0.45-0.68)$ & 0.81 & $(0.76-0.84)$ \\
\hline Hospital admissions & NR & & 1.12 & $(0.98-1.18)$ \\
\hline
\end{tabular}

Note: $\mathrm{NR}=$ not reported because of the small number of observations $(<30)$. 
1.13) and comparison communities (Table 2). This was reflected in a significantly higher incidence rate for family physician visits in this community than in the province as a whole or in the comparison communities (Table 2). The incidence rate for specialist visits in Preston was lower than that in the province as a whole, despite the significantly higher overall incidence rate (Table 2).

In addition to data on specialist visits and admissions, we had access to data on visits to the publicly provided mental health system through the Mental Health Outpatient Information System. The incidence rate for outpatient visits for mental health services was more than $40 \%$ lower in Preston than in the province as a whole and was also lower than in the comparison communities (Table 2).

\section{Interpretation}

This study allowed us to investigate the health experience of the African diaspora in North America through a comparison of a predominantly African Nova Scotian community with the white population in similar communities in the same province. In addition, we compared these data for people with access to universal health care (in Nova Scotia) with previously published data for people without such access (in the United States). The incidence rates for all 3 disease groups in Preston were 13\%-43\% higher than for Nova Scotia as a whole, and the incidence rates were also higher than for the comparison communities. These elevated incidence rates were generally consistent with the higher prevalence rates for hypertension, hyperglycemia and diabetes that have been found in community surveys of African diaspora in the United States ${ }^{2}$ and the United Kingdom ${ }^{3}$ and were reflected in an increased risk of mortality from circulatory disease. ${ }^{3}$ Our data also suggest that Preston residents received primary care and specialist care for circulatory disease and diabetes at levels generally consistent with overall incidence, which suggests that they had equitable access to these services. The only exception was the rate of hospital admissions, which was not commensurately elevated for circulatory disease.

In the case of mental health, the picture was more complicated, and comparisons with other populations were difficult, as we were unable to consider diagnostic subcategories such as schizophrenia. In Britain, people of African-Caribbean descent are 3 to 7 times more likely than the general population to receive a diagnosis of schizophrenia and are more likely to receive compulsory treatment, ${ }^{14,15}$ but they are underrepresented among patients attending family doctors for anxiety or depression and among referrals for specialist psychotherapy services. ${ }^{16}$ In Montréal, Quebec, African-Canadian inpatients with psychosis are more likely than those of European descent to be referred by police or ambulance. ${ }^{17}$ For African Nova Scotians, access to family doctors was consistent with the higher overall incidence of psychiatric disorders. However, specialist visits for mental health were lower than those for the provincial population. In terms of outpatient mental health care, visits were more than $40 \%$ lower than for the province as a whole. We might have found the same for the other diseases if data similar to that from the Mental
Health Outpatient Information System had been available. This difference may mark inequity in service delivery, consistent with work from Switzerland and elsewhere in Canada, which has shown that other marginalized populations receive fewer specialized consultations, despite universal health insurance..$^{18,19}$

\section{Limitations}

The overall rates reported here may be artificially high for some of the conditions examined, such as diabetes, because they were based on a single initial contact, regardless of whether the diagnosis was confirmed by further history or investigation. In contrast, the case definition for diabetes used by Health Canada and the Public Health Agency of Canada requires 2 outpatient visits within 730 days. ${ }^{9}$ However, because the agency's case definition for psychiatric disorder requires only 1 claim, ${ }^{10}$ we used 1 claim for all 3 disease groups, for consistency. In terms of potential bias, a wider definition would tend to minimize differences between African Nova Scotians and the general population.

Administrative data are subject to recording bias, especially for diagnoses. To minimize this source of bias, we emphasized broad disease groups. Furthermore, the databases we used captured only the incidence of treated disease, not actual rates in the community. Administrative data also lack indicators of disease severity. Although we adjusted for age, sex, educational level and socio-economic status through standardization or comparisons with similar communities, we did not take into account other potential confounders, such as marital status, alcohol consumption or tobacco use. However, US data show no evidence that African-Americans have higher rates of harmful alcohol or tobacco use than other population subgroups..$^{20,21}$

Ours was a population-level study, and the incidence rate ratios presented here cannot be attributed to individuals in Preston or the comparison communities. Only $86.1 \%$ of Preston residents are African Nova Scotians. However, given that the comparison communities were matched for a range of socio-economic factors as well as for distance to hospital, and given the marked difference in the percentage of African Nova Scotians between Preston and the comparison communities, African Nova Scotian status is a likely contributor to the differences we have described. It is also unlikely that, after adjustment for age and sex, Preston residents who were not African Nova Scotians were responsible for the greater rates, given that they represented only $13.9 \%$ of the community's population. In addition, any such bias would lead to an underestimation of the effect of African Nova Scotian status on health experience. Furthermore, we calculated incidence rate ratios relative to Nova Scotia's entire population, not just the population excluding African Nova Scotians, which would also lessen any observed differences.

Finally, our findings may be confounded by the relative isolation of the community of Preston and a possibly restricted gene pool. However, as with many other African Nova Scotian communities, Preston's roots are largely based on US refugees from the War of 1812. Genetically, therefore, Preston residents do not represent a unique group. Similarly, 
although some genetic diseases are more common in isolated populations, including some in Nova Scotia, these are almost entirely simple monogenic disorders. ${ }^{22,23}$ By contrast, the causes of chronic diseases, such as cardiovascular disease, diabetes and psychiatric disorders, are extremely complex, with nongenetic risk factors appearing to be at least as, if not more, important. ${ }^{24-26}$

\section{Implications}

These findings cannot be explained by recent immigration or language, given the history of African Nova Scotians. Similarly, they cannot be explained by socio-economic characteristics or geographic distance to a hospital, given that we took these factors into account in our analyses. As previously observed, excessive alcohol and tobacco use are also unlikely as explanations. ${ }^{20,21}$ US data have suggested that AfricanAmericans have greater exposure to environmental hazards, reflecting their general socio-economic disadvantage. ${ }^{27}$ However, this is less likely as an explanation for our results, especially since there is no known source of environmental pollution in Preston. ${ }^{28} \mathrm{~A}$ higher disease prevalence than the majority population could also be explained by differences in access to primary prevention, as opposed to treatment, or differences in response to medication. ${ }^{29-31}$

Genetic predisposition may play a role but is unlikely to be the sole reason. Studies of West Africans sharing a common genetic heritage with the African diaspora in the United States and the Caribbean have shown low rates of obesity, non-type 1 diabetes mellitus and coronary artery disease. ${ }^{2,32-34}$ Furthermore, there is an east-to-west gradient of increasing prevalence of these disorders from West Africa through the Caribbean to the United States, mirrored by a similar pattern for risk factors such as urbanization or westernization; stress; diet, including intake of energy, animal fat and salt; obesity; physical inactivity; and hypertension. ${ }^{2,32-34}$ Psychosocial stress may contribute through physiologic responses such as oversecretion of cortisol leading to, for example, impairment of feedback control and consequent heart disease. ${ }^{35}$ Further research may help in determining whether a similar interaction between genetic, biological, behavioural, psychosocial and environmental factors applies to African Nova Scotians.

In the case of mental health, discrimination is a factor in determining access to care among African-Americans, ${ }^{36}$ and further study might establish whether the same applies to African Nova Scotians. Given the lower use of specialist mental health services relative to what would be expected from overall incidence, there may also be implications for the availability, accessibility or acceptability of services for people in this group. Alternatively, they may be obtaining psychological support elsewhere. Qualitative studies could further examine barriers to health service access for this population. This research could also be extended to other conditions such as cancer, using incidence data from the Nova Scotia Cancer Registry.

This article has been peer reviewed.

Competing interests: None declared.
Contributors: Steve Kisely and Don Langille had the original idea for the article. All authors contributed to the analysis plan and design. Mikiko Terashima performed the analyses, and all authors interpreted the analyses. Steve Kisely wrote the first draft, which was revised critically for important intellectual content by the other 2 authors, before Steve Kisely incorporated amendments to produce the final draft. Each of the authors approved the final version submitted for publication.

Acknowledgements: The data used in this report were made available by the Population Health Research Unit within Dalhousie University's Department of Community Health and Epidemiology. The Population Health Research Unit is a university-based research and support group that conducts systematic research into population health, health services and their interrelationships. The Nova Scotia provincial government supplies the unit with complete medicare and hospital files suitable for research purposes. The unit also has access to a variety of other data sources, including clinical databases and large-scale population surveys. Although the research presented here was based on data obtained from the unit, the observations and opinions expressed are those of the authors and do not represent those of the Population Health Research Unit.

Funding:This project was funded by the Capital Health Research Fund.

\section{REFERENCES}

1. Visible minority population, by province and territory (2001 Census): Newfoundland and Labrador, Prince Edward Island, Nova Scotia and New Brunswick. Ottawa: Statistics Canada; 2005. Available: www40.statcan.ca/101/cst01/demo52a .htm (accessed 2008 Aug 20).

2. Schuster DP, Gaillard T, Osei K. The cardiometabolic syndrome in persons of the African diaspora: challenges and opportunities. J Cardiometab Syndr 2007;2:260-6.

3. NHS Centre for Reviews and Dissemination; Social Policy Research Unit. Ethnicity and health: reviews of literature and guidance for purchasers in the areas of cardiovascular disease, mental health and haemoglobinopathies [report 5]. York (UK): University of York, The Centre; 1996.

4. Wu Z, Schimmele CM. Racial/ethnic variation in functional and self-reported health. Am J Public Health 2005;95:710-6.

5. Quan H, Fong A, DeCoster C, et al. Variation in health services utilization among ethnic populations. CMAJ 2006;174:787-91.

6. Pachai B, Bishop H. Historic black Nova Scotia. Halifax: Nimbus Publishing; 2006

7. Immigrant population by place of birth, by province and territory (2006 census) (Newfoundland and Labrador, Prince Edward Island, Nova Scotia). Ottawa: Statistics Canada; 2006. Available: www40.statcan.ca/101/cst01/demo34a.htm (accessed 2008 Aug 20).

8. Nova Scotia Community Counts. Data for 2004-2007. Halifax: Province of Nova Scotia; 2007 Available: www.gov.ns.ca/finance/communitycounts (accessed 2008 Aug 20).

9. National Diabetes Surveillance System. Responding to the challenge of diabetes in Canada. Ottawa: Health Canada; 2003. Available: www.phac-aspc.gc.ca/ccdpccpcmc/ndss-snsd/english/pubs_reports/pdf/WEB_NDSS_English_Report-nocover.pdf (accessed 2008 Aug 20).

10. Gilbert C, Jones W, Schopflocher D, et al. Use of provincial administrative data for surveillance of mental disorders: feasibility study. Ottawa: Public Health Agency of Canada, Centre for Chronic Disease Prevention and Control, Surveillance Division; 2007.

11. Williams JI, Young W. Inventory of studies on the accuracy of Canadian health administrative databases. Toronto: Institute for Clinical Evaluative Sciences in Ontario; 1996.

12. Wilkins R. PCCF + version $4 G$ user's guide. Automated geographic coding based on the Statistics Canada Postal Code Conversion files, including postal codes to October 2005. Ottawa: Statistics Canada, Health Analysis and Measurement Group; 2005. Cat no. 82F0086-XDB.

13. Washington State, Department of Health. Guidelines for using confidence intervals for public health assessment. Seattle: The Department; 2002. Available: www.doh .wa.gov/Data/Guidelines/ConfIntguide.htm (accessed 2008 Aug 20).

14. McColl AJ. Schizophrenia. In: McColl AJ, Gulliford MC, editors. Population health outcome indicators for the NHS: a feasibility study. London (UK): Royal Colleges of Physicians of the United Kingdom, Faculty of Public Health Medicine; 1993. p. 85-91.

15. Koffman J, Fulop NJ, Pashley D, et al. Ethnicity and use of acute psychiatric beds: one-day survey in North and South Thames regions. Br J Psychiatry 1997;171: 238-41.

16. Balarajan R, Raleigh VS. The health of the nation. Ethnicity and health: a guide for the NHS. London (UK): Department of Health; 1993.

17. Jarvis EG, Kirmayer LJ, Jarvis GK, et al. The role of Afro-Canadian status in police or ambulance referral to emergency psychiatric services. Psychiatr Serv 2005 56:705-10.

18. Roos NP, Mustard CA. Variation in health and health care use by socioeconomic status in Winnipeg, Canada: Does the system work well? Yes and no. Milbank $Q$ 1997;75:89-111. 
19. Gutzwiller F, La Vecchia C, Levi F, et al. Education, disease prevalence and health service utilization in the Swiss Nation Health Survey "SOMIPOPS". Prev Med 1989;18:452-9.

20. National Center for Health Statistics. Age-sex-adjusted percent of adults aged 18 years and over with excessive alcohol consumption, by race/ethnicity: United States, 2001. Washington: National Center for Health Statistics; 2002. Available: www.cdc.gov/nchs/about/major/nhis/released200207/figure09_3.htm (accessed 2008 Aug 20)

21. Moolchan ET, Fagan P, Fernander AF, et al. Addressing tobacco-related health disparities. Addiction 2007;102 (Suppl 2):30-42.

22. Cooper RS. Race, genes, and health - new wine in old bottles? Int J Epidemiol 2003;32:23-5.

23. Winsor EJ, Welch JP. Genetic and demographic aspects of Nova Scotia NiemannPick disease (type D). Am J Hum Genet 1978;30:530-8.

24. Rotimi CN, Cooper RS, Cao G, et al. Maximum-likelihood generalized heritability estimate for blood pressure in Nigerian families. Hypertension 1999;33:874-8.

25. Wilson PW, Meigs JB, Sullivan L, et al. Prediction of incident diabetes mellitus in middle-aged adults: the Framingham Offspring Study. Arch Intern Med 2007;167: 1068-74.

26. Merikangas KR, Swendsen JD. Genetic epidemiology of psychiatric disorders. Epidemiol Rev 1997; 19:144-55.

27. Brown P. Race, class, and environmental health — a review and systematization of the literature. Environ Res 1995;69:15-30.

28. Municipal solid waste disposal sites. Halifax: Nova Scotia Department of Environment; 2008. Available: www.gov.ns.ca/nse/waste/solidwastedisposal.asp (accessed 2008 Aug 20)
29. Yancy CW. The prevention of heart failure in minority communities and discrepancies in health care delivery systems. Med Clin North Am 2004;88:1347-68.

30. Wolff M, Bates T, Beck B, et al. Cancer prevention in underserved African American communities: barriers and effective strategies - a review of the literature. WMJ 2003;102:36-40.

31. Bjornsson TD, Wagner JA, Donahue SR, et al. A review and assessment of potential sources of ethnic differences in drug responsiveness. J Clin Pharmacol 2003, 43.943-67.

32. Elbein SC. Evaluation of polymorphisms known to contribute to risk for diabetes in African and African-American populations. Curr Opin Clin Nutr Metab Care 2007;10:415-9.

33. Daniel HI, Rotimi CN. Genetic epidemiology of hypertension: an update on the African diaspora. Ethn Dis 2003;13(Suppl 2):S53-66.

34. Luke A, Cooper RS, Prewitt TE, et al. Nutritional consequences of the African diaspora. Annu Rev Nutr 2001;21:47-71.

35. McEwen BS. Stress, adaptation, and disease: allostasis and allostatic load. Ann N Y Acad Sci 1998;840:33-44.

36. Campinha-Bacote J. Becoming culturally competent in ethnic psychopharmacology. J Psychosoc Nurs Ment Health Serv 2007;45:27-33.

Correspondence to: Dr. Steve Kisely, School of Medicine, Rm. 2.15d, Building LO3, Logan Campus, Griffith University, University Dr., Meadowbrook, Queensland 4131, Australia; fax 61073382 1338; s.kisely@griffith.edu.au

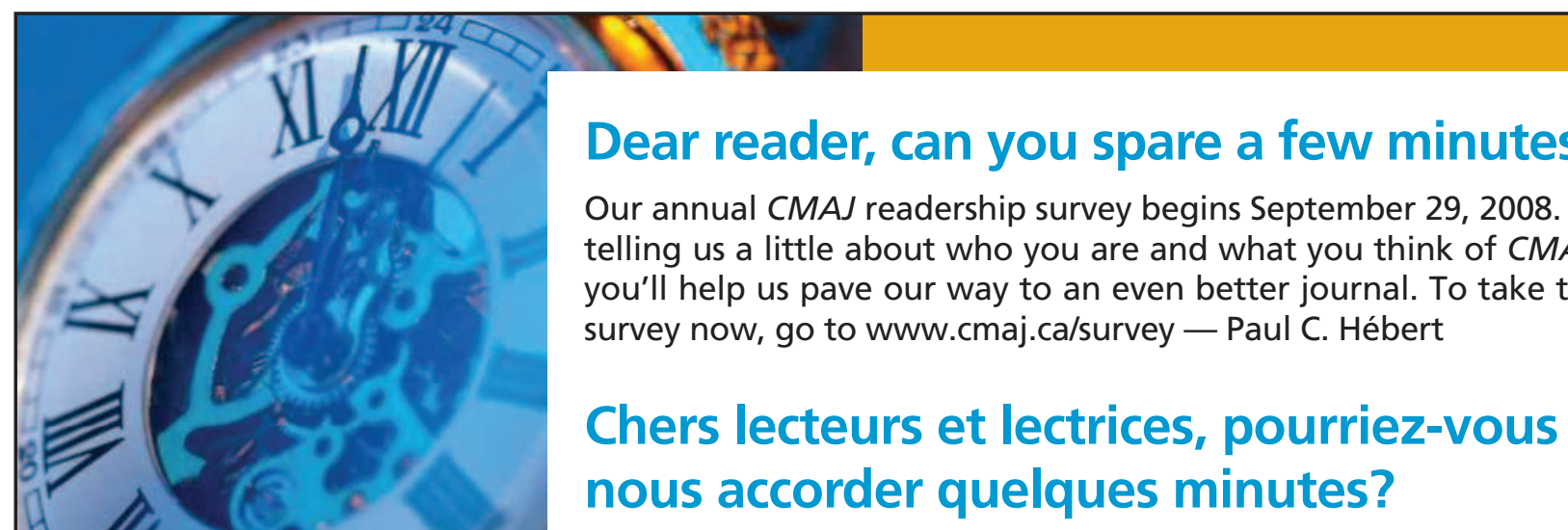

Le sondage annuel auprès des lecteurs du JAMC débutera le 29 septembre, 2008. En nous parlant un peu de vous et de ce que vous pensez du JAMC, vous nous aiderez à améliorer encore le journal. Pour répondre au sondage maintenant, allez à www.cmaj.ca/survey - Paul C. Hébert 